\title{
Association between Diabetes Mellitus and Periodontal Diseases: A Survey of the Opinions of Dental Professionals
}

\author{
Emad AlShwaimi $^{a}$ Majdy Idrees $^{b} \quad$ Zeina Berri $^{c}$ Haytham El-Sakka ${ }^{d}$ \\ Omar Kujan $^{\text {d }}$ \\ ${ }^{a}$ Restorative Dental Sciences, College of Dentistry, Imam Abdulrahman Bin Faisal University (University of \\ Dammam), Dammam, Saudi Arabia; ${ }^{b}$ Private Dental Sector, Manama, Kingdom of Bahrain; ' Department of Oral \\ Medicine and Diagnostic Sciences, Al-Farabi College for Dentistry and Nursing, Al-Farabi Colleges, Riyadh, Saudi

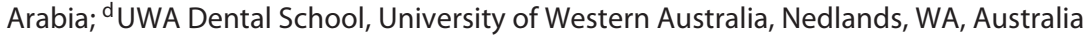

\section{Significance of the Study}

- This cross-sectional survey of the dental professional team reinforces the importance of the knowledge on periodontal disease-diabetes interactions to provide high-quality service and safe practice. The study also highlights the need of dentists and dental assistants for up-to-date awareness on current trends of the diagnosis and management of diabetes.

\section{Keywords}

Survey · Perception · Diabetes mellitus · Oral health ·

Periodontal diseases $\cdot$ Dental professionals

\begin{abstract}
Objective: This cross-sectional survey aimed to assess the knowledge of dentists and dental assistants practicing in Saudi Arabia regarding diabetes mellitus (DM) and periodontal diseases. Subjects and Methods: We used a pretested, closed-ended, multiple-choice questionnaire covering 2 principal sections: the assessment of previous educational training and practice, and the knowledge and scientific background regarding DM and periodontal diseases. The responses were grouped using the Likert-type scale. Results: The questionnaire showed a high reliability value of 0.805 as determined by a Cronbach's a. Out of 365 subjects who were
\end{abstract}

initially interviewed, 239 subjects participated (response rate $65.5 \%$ ): general dentists (45.6\%) and dental hygienists and assistants (54.4\%). Of the participating dentists, $70.4 \%$ were males; in contrast, $87.7 \%$ of dental assistants were female. Eighty-five percent of the participants strongly agreed that evidence supports the association between periodontal diseases and DM. Remarkably, dental assistants (78\%) agreed more than dentists (68.5\%) that diabetic patients with periodontal conditions would have worse glycemic control compared to diabetic patients with no periodontal diseases. Seventy-five percent of the respondents were confident about performing oral health screening for diabetic patients. Significantly more dental assistants showed their desire to expand their practice to include oral health screening (85\%) and education compared to dentists (74\%). Conclusions: Both dentists and dental assistants in Saudi Arabia revealed a satisfactory knowledge level regarding the periodontal

\begin{tabular}{ll}
\hline KARGER & $\begin{array}{l}\text { (c) } 2018 \text { The Author(s) } \\
\text { Published by S. Karger AG, Basel }\end{array}$ \\
E-Mail karger@karger.com & $\begin{array}{l}\text { This is an Open Access article licensed under the Creative Commons } \\
\text { Attribution-NonCommercial-4.0 International License (CC BY-NC) } \\
\text { (http://www.karger.com/Services/OpenAccessLicense), applicable to } \\
\text { the online version of the article only. Usage and distribution for } \\
\text { commercial purposes requires written permission. }\end{array}$
\end{tabular}


disease-diabetes interactions with no significant difference between the two groups. Further studies are recommended to assess the attitude of dental care providers while dealing with diabetic patients.

(C) 2018 The Author(s)

Published by S. Karger AG, Basel

\section{Introduction}

Diabetes mellitus (DM) is a serious global health burden. According to the International Diabetes Federation 2013 update, $8.3 \%$ of adults (i.e., 382 million people) were diabetic worldwide; by 2035, this number will rise to 592 million [1]. It costs around USD 1,200 billion to diagnose, treat, and care for both type 1 and type $2 \mathrm{DM}$ patients globally [2]. The disorder is rapidly increasing out of proportion in both developed and developing countries, especially type $2 \mathrm{DM}$, which is associated with modern lifestyle habits such as reduced physical activity, diet, obesity, and genetic factors [2]. Interestingly, 3 of the world's top 10 countries with the highest prevalence of diabetes are in the Middle East: Saudi Arabia (24\%), Kuwait (23\%), and Qatar (23\%) [1].

DM increases the susceptibility to, and severity of, infections due to the reduction in functional activity of neutrophils (first line of defense) and consequently contributes to delayed wound healing [3]. Clinical investigations in diabetic patients clearly demonstrated consistent defects in neutrophil chemotactic, phagocytic, and microbicidal activities $[4,5]$.

If left untreated, DM can lead to a number of diseases and chronic systemic complications largely caused by hyperglycemia-induced oxidative stress as well as cellular and molecular impairment in neural and vascular structure and function, including neuropathy, angiopathy, retinopathy, nephropathy, and cardiovascular complications $[6,7]$. DM-induced complications may in turn lead to the dysfunction of cells, tissue, and organ systems, and subsequently death [2].

Periodontal disease is now considered a DM-related complication, with a two-way relationship between DM and periodontal diseases $[8,9]$.

While diabetes increases the risk of periodontal diseases, the severity of periodontal inflammation negatively affects glycemic control [8]. Mealey et al. [10] reported that the risk of periodontitis is increased approximately threefold in diabetic patients compared to nondiabetics; in addition, the risk is increased with poor glycemic control [11]. More importantly, there is evidence to support that the severity of periodontal diseases has a negative impact on glycemic control [12-15]. Additionally, periodontal treatment improves glycemic control in type 2 diabetic patients for at least 3 months [16].

Interestingly, regardless of the well-known negative consequences of diabetes on oral health, many previous studies revealed that most of the diabetic patients did not have enough knowledge about the negative impacts of diabetes on their oral health [17-20]. At the same time, many studies highlighted the fact that diabetic patients have more knowledge about the systemic consequences of diabetes than about diabetes-related oral complications $[19,21]$.

To some extent, the cause for this lack of awareness may be attributed to workers in the health services, as they may not provide adequate information regarding this issue to their patients [17]. Bowyer et al. [17] demonstrated that approximately $70 \%$ of diabetic patients had never received any instruction about oral health care related to their DM from their dental professionals. Moreover, a recent study conducted in 2017 revealed that most health care providers responsible for managing DM in patients were not addressing oral health care in their patients primarily due to limited knowledge and limited time to deal with DM-related oral complications [22].

However, in order to enhance the oral health status and to reduce the risk of oral manifestations, workers in the dental field have to take the responsibility and develop proper programs to educate patients who are diagnosed with or at risk of developing DM, and raise the level of awareness about the oral conditions related to diabetes [19]. This survey aimed to assess the level of knowledge on periodontal disease-diabetes interactions in dentists and dental assistants in Saudi Arabia.

\section{Subjects and Methods}

\section{Study Design and Sample Collection}

This is a cross-sectional survey of dental assistants, dental hygienists, and dental practitioners at 2 major cities in Saudi Arabia, Jeddah and Dammam, in collaboration with the dental colleges of the University of Dammam (Dammam) and the King Abdulaziz University (Jeddah). The survey was conducted over a period of 2 months (April and May 2016). Approval for the study was taken from the Research and Ethics Committee at the University of Dammam. All procedures were performed in accordance with the Principles of the Helsinki Declaration. All participants were asked to sign a consent form after explaining the objectives of this study. The names and mailing addresses of participants were obtained by direct personal contacts with participants who registered to attend the 4th International Conference of the Faculty of Dentistry, King Abdulaziz University, in October 2015, and the 12th Annual Dental Symposium of the Damman University in April 2015. All par- 
ticipants were informed that they would be contacted for research purposes. All participants were then contacted to arrange personal appointments. The survey was distributed by 3 investigators to participants (dental assistants, dental hygienists, and general dental practitioners) working in private dental clinics and hospitals in Saudi Arabia. Demographic data were collected from all participants, which included gender, age, years of practicing, qualifications, and country of graduation.

\section{Questionnaire Development}

Survey questions were formulated in English to prompt either multiple-choice or Likert-scale responses according to the purposes of this study. The language in the questionnaire was audited by a professional in order to assure absence of grammatical mistakes or ambiguous terms. The questionnaire was pilot tested before finalizing by asking 25 general dental practitioners ( 16 females and 9 males) and 7 dental assistants (5 females and 2 males), who had at least 10 years of experience to answer the questionnaire. Participants of the pilot study were selected from dental professional teams at the Dammam Dental Hospital. After completion of the pilot questions, each respondent was interviewed personally to obtain direct feedback about the design, clearance, language, feasibility, and reasonability of questions. Feedback was then collated and used to refine the questions.

\section{Description of Questionnaire Items}

Seventeen items of the questionnaire were designed to address the attitude, knowledge, and behavior of dental practitioners toward the relation between periodontal diseases and diabetes. Items were divided into 2 principal sections; the first section includes 6 items for the assessment of previous educational training and practice behavior, and the second section includes 11 items for the assessment of knowledge and scientific background regarding DM and periodontal diseases.

In the first section of the questionnaire, 3 items elicited information on the number of educational hours or clinical requirements taken by participants in the area of systemic diseases and periodontal problems either in their undergraduate studies or as continuing medical education. The other 3 items addressed the specific experience of dental professionals while dealing with diabetic patients, which included the average number of diabetic patients per year and the percentage of those who developed oral complications, in addition to the frequency of routine oral examination performed by participants on their patients.

In the next section, items were formulated to appraise the knowledge of dental care providers on the relationship between periodontal diseases and DM. A Likert-type style was used in this section with 5 levels of response options ranging from strongly agree to strongly disagree. Items within this group were categorized into 4 main categories:

1. general knowledge about DM and knowledge of DM-related studies and evidence-based practices (3 items) (Table 2),

2. items on the impact of DM on the periodontium (2 items) (Fig. 3),

3. items on the impact of periodontal diseases on glycemic control (3 items) (Fig. 3), and

4. items to evaluate the desire and willingness of dental providers to develop and learn more about the relationship between DM and periodontal diseases ( 3 items) (Fig. 4).

Perception of the Association between Diabetes and Periodontal Diseases

\section{Data Analysis}

Data were analyzed using the Statistical Package for Social Sciences (SPSS) software (version 22.0). The Fisher exact test was used to assess whether the respondents' responses on knowledge and practice were influenced by participants' characteristics. Binary logistic regression analysis was performed to examine the role of age, years of experience, and country of graduation as possible predictors for the level of knowledge. A $p$ value below 0.05 was considered statistically significant.

\section{Results}

\section{Study Subjects}

Out of 365 subjects who were initially contacted, 239 subjects approved to participate (response rate 65.5\%): 88 males (36.8\%) and 151 females (63.2\%). Participants ranged in age from 20 to 54 years; the mean age was 30.19 $( \pm 7.98)$ years. The mean age of dentists was $26.83( \pm 4.9)$ years, while it was 33.14 (8.9) years for dental assistants.

As a consequence of the limited number of dental hygienists in the study (7 subjects; $2.9 \%$ ), dental hygienists were included into the same group as dental assistants. Participants were divided into 2 groups according to their professional qualifications as follows:

- dental assistants $(n=130 ; 54.4 \%)$ and

- general dentists $(n=109 ; 45.6 \%)$.

Significantly, most of the participating dentists were male $(70.4 \%)$, compared to $29.4 \%$ of female dentists ( $p=$ 0.001 ); in contrast, $87.7 \%$ of dental assistants were female, which was significantly higher than the percentage of male dental assistants $(12.3 \% ; p=0.001)$.

The reliability value of the questionnaire showed a high level of internal consistency, as determined by Cronbach's $\alpha$ of 0.805 .

\section{Assessment of Previous Education and Practice Type}

Six questions in the questionnaire aimed to assess the professional preparation of the dental care providers regarding the relationship between periodontal diseases and DM.

When the participants were asked about the number of study hours regarding oral and periodontal health and systemic diseases in their undergraduate course of study, dentists significantly responded that they studied this for $5-9 \mathrm{~h}(p=0.007)$, while for dental assistants it was more than 9 h (Fig. 1).

In addition, dentists significantly revealed that they took more continuing medical education courses regarding systemic diseases and its impact on oral health in the previous year than dental assistants $(p=0.02)$ (Fig. 2). 


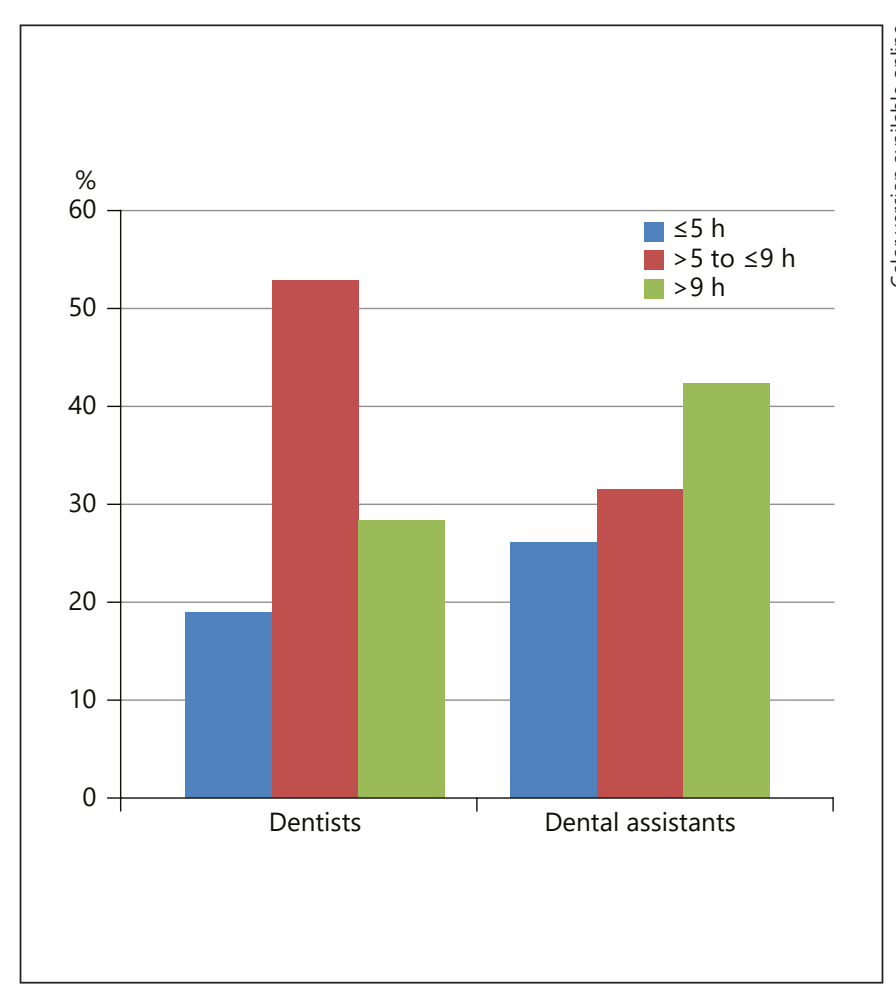

Fig. 1. How many hours of material regarding oral health/periodontal health were covered in the curriculum?

Likewise, most of the dentists significantly specified that they have clinical requirements regarding the assessment of gingiva and teeth in their undergraduate education compared to dental assistants $(p=0.001)$ (Fig. 2).

When dental professionals were asked about the average number of diabetic patients that they encountered in the past year, less than $1 \%$ of participants revealed that more than $60 \%$ of their patients are diabetic, while significantly more dental assistants answered that less than $10 \%$ of their patients were diabetic compared to dentists (61.3 and 29.2\%, respectively) (Table 1). More than half of dental assistants revealed that the percentage of diabetic patients who experience periodontal problems could be in the range from 0 to $10 \%$, which was significantly higher than the percentage of dentists $(17 \% ; p=$ 0.001) (Table 1).

More than $67 \%$ of dental assistants stated that they examine their patients at every visit compared to about $44 \%$ of dentists; moreover, significantly more dentists than dental assistants (32.7 vs. $9.5 \%$, respectively) stated that they examine their patients just in the initial visit (Table 1).

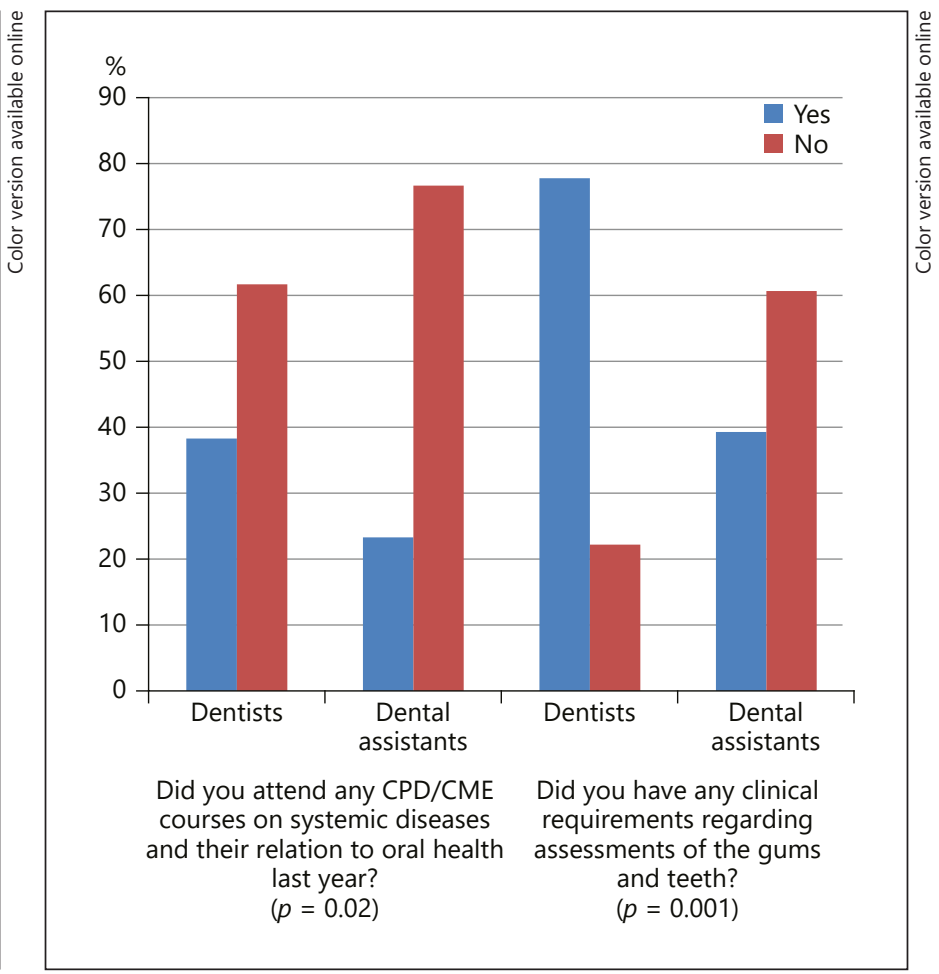

Fig. 2. Assessment of previous educational preparation. CME, continuing medical education. CBD, continuing professional development.

\section{Assessment of Knowledge and Background regarding $D M$ and Periodontal Diseases}

Eleven questions were designed to evaluate the level of awareness and knowledge among workers in the dental field regarding the association between periodontal diseases and DM.

\section{Link between DM and Periodontal Diseases}

More than $86 \%$ of participants agreed that evidence supports the association between periodontal diseases and systemic conditions. Similarly, about $85 \%$ of our correspondents either agreed or strongly agreed that the evidence strongly associates DM with periodontal diseases. In addition, more than three-quarters of study participants revealed that they had previous knowledge of the association between DM and periodontal health. No significant differences were seen between dentists and dental assistants while responding to these items (Table 2).

\section{Impact of DM on Periodontium}

More than $85 \%$ of study participants agreed that the risk of developing severe periodontal diseases is increased 
Table 1. Assessment of previous experience while dealing with diabetic patients

\begin{tabular}{|c|c|c|c|c|}
\hline Question & & \multicolumn{2}{|c|}{ Response, \% } & $p$ value \\
\hline $\begin{array}{l}\text { According to your experience, please specify the } \\
\text { percentage of patients with diabetes who } \\
\text { experience periodontal disease }\end{array}$ & $\begin{array}{l}0-10 \% \\
11-20 \% \\
21-40 \% \\
>40 \%\end{array}$ & $\begin{array}{l}16.8^{1} \\
29 \\
33.6 \\
20.6\end{array}$ & $\begin{array}{l}51.7^{1} \\
14.4 \\
19.5 \\
14.4\end{array}$ & 0.001 \\
\hline $\begin{array}{l}\text { On average, please specify the frequency of oral } \\
\text { examinations you perform for your patients }\end{array}$ & $\begin{array}{l}\text { At every visit } \\
\text { When a patient mentions a problem } \\
\text { At initial visit only } \\
\text { Rarely } \\
\text { Never }\end{array}$ & $\begin{array}{l}44.2 \\
22.1 \\
32.7^{1} \\
1 \\
0\end{array}$ & $\begin{array}{l}67.2 \\
9.5 \\
9.5^{1} \\
4.3 \\
9.5\end{array}$ & 0.001 \\
\hline
\end{tabular}

${ }^{1}$ Fisher exact test.

Table 2. Assessment of general knowledge about the evidence and studies related to the relation between diabetes mellitus (DM) and periodontal diseases (PD)

\begin{tabular}{|c|c|c|c|c|c|}
\hline Question & $\begin{array}{l}\text { Strongly } \\
\text { agree, } \%\end{array}$ & $\begin{array}{l}\text { Agree, } \\
\%\end{array}$ & $\begin{array}{l}\text { Undecided, } \\
\%\end{array}$ & $\begin{array}{l}\text { Disagree, } \\
\%\end{array}$ & $\begin{array}{l}\text { Strongly } \\
\text { disagree, } \%\end{array}$ \\
\hline $\begin{array}{l}\text { The research is strong regarding } \\
\text { a relationship between PD and systemic health }\end{array}$ & 41.8 & 44.4 & 5.2 & 2.6 & 6 \\
\hline $\begin{array}{l}\text { The research evidence is strong regarding an association } \\
\text { between PD and DM }\end{array}$ & 39.3 & 45 & 7.9 & 3.5 & 4.4 \\
\hline I am knowledgeable regarding the studies linking PD and DM & 32 & 45.8 & 12 & 5.3 & 4.9 \\
\hline
\end{tabular}

among diabetic patients (Fig. 3). Similarly, more than $81 \%$ of participants indicated knowledge (agree or strongly agree) that poor glycemic control would lead to more severe periodontal problems (Fig. 3).

\section{Impact of Periodontal Diseases on the Level of \\ Glycemic Control}

A majority of respondents (92.6\%) either agreed or strongly agreed that good periodontal health is important to overall health. In addition, respondents to the survey generally agreed (73.7\%) that diabetic patients with periodontal conditions would result in poor glycemic control compared to diabetic patients without periodontal com- plications. However, in response to this item, significantly more dental assistants than dentists agreed (78 vs. $68.5 \%$, respectively, $p=0.002$ ). However, less than $68 \%$ of our participants adopted the idea that periodontal treatment could improve glycemic control (Fig. 3).

\section{Evaluation of the Desire and Willingness to Learn}

More about the Relation between DM and Periodontal

\section{Diseases}

About three-quarters of the study participants were confident about their ability to perform oral health screening for diabetic patients; at the same time, $93 \%$ of dental assistants and $81 \%$ of dentists demonstrated their 


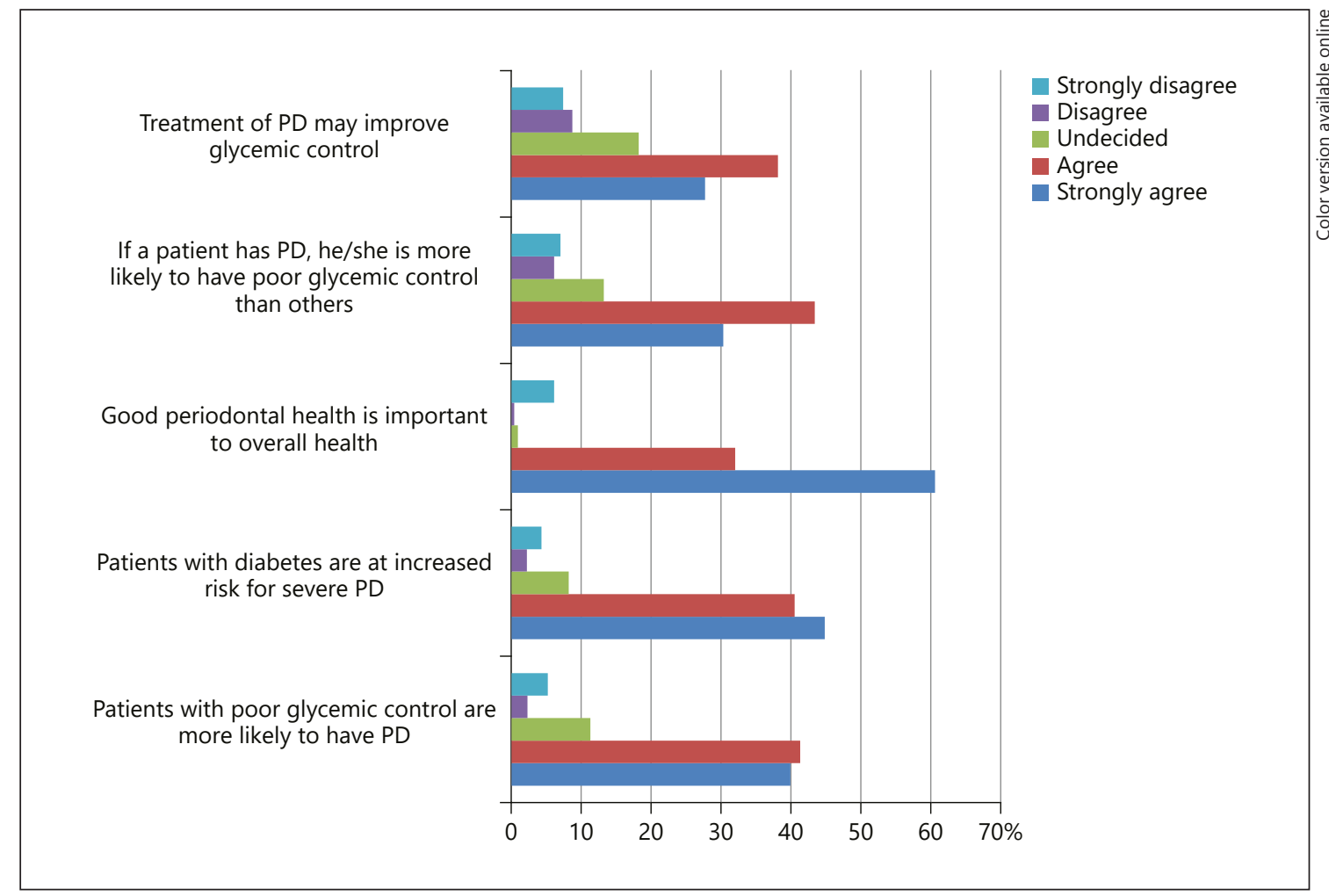

Fig. 3. Assessment of knowledge regarding the impact of diabetes mellitus and periodontal diseases (PD) on each other.

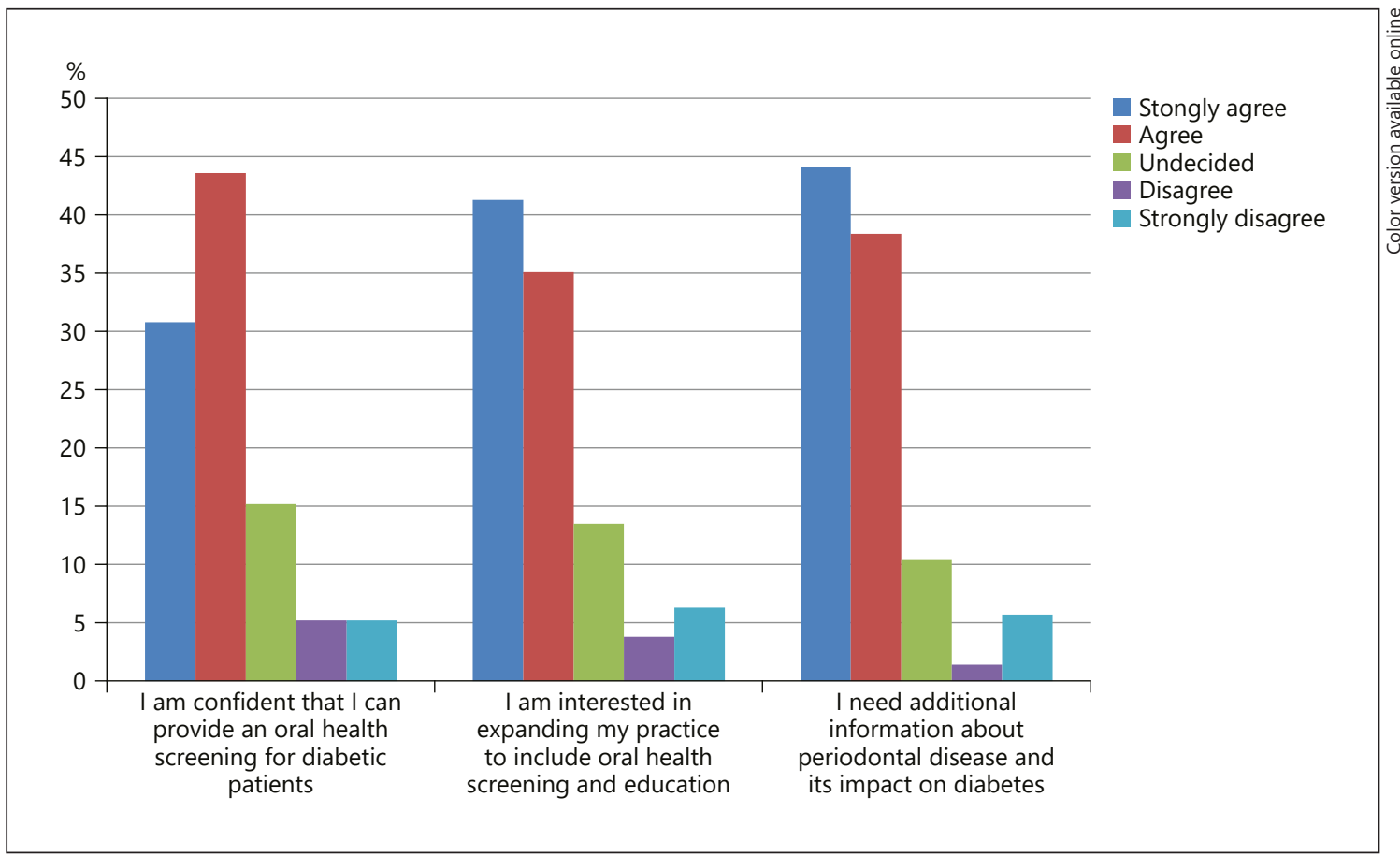

Fig. 4. Evaluation of the desire to learn and develop knowledge among dental care providers. 
willingness to learn more about the link between periodontal diseases and DM (Fig. 4). In addition, significantly more dental assistants demonstrated a desire to expand their practice to include oral health screening and education compared to dentists ( 85 vs. $74 \%$, respectively) (Fig. 4).

\section{Multivariate Analysis}

Multivariate regression analysis was used to validate the role of gender, age, years of experience, and country of graduation as possible predictors. However, none of these previously mentioned variables played a role as a significant predictor.

\section{Discussion}

The global prevalence of DM is increasing in an accelerated manner; the number of deaths per year as a result of diabetic complications is about 5 million, which is significantly higher than the number of deaths per year from AIDS, tuberculosis, and malaria [23].

However, it is clear that elevating the level of awareness among diabetic patients about the complications of $\mathrm{DM}$ is essential to overcome any negative consequences of diabetes on the quality of life. At the same time, increasing the awareness of health care providers will probably improve their attitude and behavior towards the management of diabetic patients. In addition, assessing the status of periodontal health is a standard recommendation for delivering comprehensive diabetes care in the USA [24] and other places worldwide [23].

This study was designed to evaluate the knowledge of dental care providers in Saudi Arabia toward the relation between diabetes and periodontal health. In order to survey a large geographic area, our study was conducted in 2 different geographic locations that represent the 2 major cities in Saudi Arabia: Jeddah (western province) and Dammam (eastern province).

The length of the study for dentists is more than that of dental assistants; in addition, the accreditation requirements for dentists is more demanding than that of dental assistants; thus, it is not reasonable to expect that both dentists and dental assistants have the same levels of knowledge. However, the purpose of the study was to evaluate the level of knowledge among the dental care providers regarding interactions between diabetes and periodontal diseases in order to evaluate their role in educating their patients rather than comparing the differences among them.

Perception of the Association between Diabetes and Periodontal Diseases
Our respondents were asked about their previous education in the area of periodontal diseases-diabetes interactions. Dentists had more often clinical exposure to the oral-systemic association than dental assistants; in contrast, the number of curricular theoretical hours on systemic diseases was higher for dental assistants than dentists. However, differences in the undergraduate curricula of dentistry and dental-assistant programs could explain the differences between both groups.

About $40 \%$ of our respondent dentists revealed that they attended continuing medical education related to oral-systemic diseases, which was significantly higher than the percentage of dental assistants. This variation could be explained by a variation in the rules applied on health care professionals from the national health authorities in Saudi Arabia regarding the requirements for continuing education. However, the role of formal training is important in developing the knowledge and level of confidence among health practitioners while dealing with diabetic patients in the clinics. Esmeili et al. [25] demonstrated that formal training in the area of diabetes is a significant predictor of both providing good service for diabetics and advising patients about diabetes and its periodontal complications.

The prevalence of diabetes in Saudi Arabia (24\%) was among the highest 10 globally [1]. More than $60 \%$ of our participating dentists said that the percentage of diabetic patients range from 11 to $40 \%$. However, this could be a limitation of our study, where the sample was limited to 2 major cities without inclusion of rural areas; thereby, the percentage of diabetic subjects in our study may not be generalized to the whole population in Saudi Arabia. At the same time, our results revealed that significantly more dental assistants answered that less than $10 \%$ of their patients were diabetic compared to dentists, and this could be attributed to the supposition that medically compromised patients prefer visiting dentists instead of dental assistants. However, further studies have to be conducted among medically compromised patients to assess their opinions regarding this. On the other hand, the negative impact of diabetes on periodontal health has been studied extensively [10, 26, 27]. Furthermore, the level of glycemic control plays a significant role in the severity of periodontal infection [27]. Hence, it is not uncommon to find a high level of awareness related to this among dental care providers. Most of our respondents were aware of the diabetes-periodontium relationship, which is similar to previous studies in the same field [28, $29]$. However, our results revealed that about $80 \%$ of respondents agreed that the presence of DM would increase

Med Princ Pract 2019;28:141-149 
the risk of severe periodontal diseases, which is lower than in a previous study conducted in the USA among the dental hygienists when the agreement rate was almost $100 \%$ [30]. Nevertheless, a previous study conducted in Kuwait in 2011 revealed that the level of knowledge regarding oral-related complications in diabetes was significantly decreased from more than 88 to about 50\% when moved toward more specific periodontal complications such as tooth loss and periodontal abscess [29]. However, another limitation of our study is the absence of items directed to assess specific periodontal complications related to diabetes.

Similarly, it is encouraging that more than $90 \%$ of our respondents agreed that good periodontal health is important to overall health. Nevertheless, when respondents were asked about the impact of periodontal health on the level of glycemic control, the extent of agreement was still high, but less than in previous items, which could be explained by the controversy over this issue, where the evidence does not document this relationship strongly.

Hema et al. [31] revealed that $73 \%$ of dentists felt that they were effective in addressing diabetics in their clinics, which is consistent with our results that showed about $80 \%$ of our subjects were confident in treating diabetic patients. However, these findings are in contrast with findings of Esmeili et al. [25], who found that just a third of dentists were confident in dealing with diabetic patients. Findings of the previous study were attributed to the fact that the participating dentists had been out of school for about 15 years; hence, their theoretical and practical knowledge was perhaps not up to date and they may not have kept up with recent research findings in this field. At the same time, the majority of our respondents showed their interest in expanding their practice to include oral health screening and patient education; in addition, they had the desire to learn new information regarding the oral-systemic association. This indicates a high level of awareness among dental care providers in Saudi Arabia regarding the desire for self-development and improvement in practice.

\section{Conclusion}

The level of awareness and knowledge among dental care providers in Saudi Arabia was satisfactory; no significant differences were seen between the dentists and dental assistants while responding to the knowledge-related items. However, future studies are recommended in this field to include items on specific periodontal complications and investigating the attitude of dental care providers while dealing with diabetic patients.

\section{Disclosure Statement}

We declare that we have no potential conflicts of interest.

\section{References}

1 International Diabetes Federation. IDF diabetes atlas. 2017. http://www.diabetesatlas. org/ (accessed 13/10/2017).

2 Lotfy M, Adeghate J, Kalasz H, Singh J, Adeghate E. Chronic complications of diabetes mellitus: a mini review. Curr Diabetes Rev. 2017;13(1):3-10.

3 Alba-Loureiro TC, Munhoz CD, Martins JO, Cerchiaro GA, Scavone C, Curi R, et al. Neutrophil function and metabolism in individuals with diabetes mellitus. Braz J Med Biol Res. 2007 Aug;40(8):1037-44

4 Yano H, Kinoshita M, Fujino K, Nakashima M, Yamamoto Y, Miyazaki H, et al. Insulin treatment directly restores neutrophil phagocytosis and bactericidal activity in diabetic mice and thereby improves surgical site Staphylococcus aureus infection. Infect Immun. 2012 Dec;80(12):4409-16.
5 Lecube A, Pachón G, Petriz J, Hernández C, Simó R. Phagocytic activity is impaired in type 2 diabetes mellitus and increases after metabolic improvement. PLoS One. 2011; 6(8):e23366.

6 American Diabetes Association. Diagnosis and classification of diabetes mellitus. Diabetes Care. 2009 Jan;32 suppl 1:S62-7.

7 Leite RS, Marlow NM, Fernandes JK, Hermayer K. Oral health and type 2 diabetes. Am J Med Sci. 2013 Apr;345(4):271-3.

8 Preshaw PM, Alba AL, Herrera D, Jepsen S, Konstantinidis A, Makrilakis K, et al. Periodontitis and diabetes: a two-way relationship. Diabetologia. 2012 Jan;55(1):21-31.

9 Löe H. Periodontal disease. The sixth complication of diabetes mellitus. Diabetes Care. 1993 Jan;16(1):329-34.

10 Mealey BL, Oates TW; American Academy of Periodontology. Diabetes mellitus and periodontal diseases. J Periodontol. 2006 Aug; 77(8):1289-303.
11 Taylor GW, Burt BA, Becker MP, Genco RJ, Shlossman M. Glycemic control and alveolar bone loss progression in type 2 diabetes. Ann Periodontol. 1998 Jul;3(1):30-9.

12 Lamster IB, DePaola DP, Oppermann RV, Papapanou PN, Wilder RS. The relationship of periodontal disease to diseases and disorders at distant sites: communication to health care professionals and patients. J Am Dent Assoc. 2008 Oct;139(10):1389-97.

13 Taylor GW, Burt BA, Becker MP, Genco RJ, Shlossman M, Knowler WC, et al. Severe periodontitis and risk for poor glycemic control in patients with non-insulin-dependent diabetes mellitus. J Periodontol. 1996;67 suppl 10S:1085-93. 
14 Arora N, Papapanou PN, Rosenbaum M, Jacobs DR Jr, Desvarieux M, Demmer RT. Periodontal infection, impaired fasting glucose and impaired glucose tolerance: results from the Continuous National Health and Nutrition Examination Survey 2009-2010. J Clin Periodontol. 2014 Jul;41(7):643-52.

15 Shultis WA, Weil EJ, Looker HC, Curtis JM, Shlossman M, Genco RJ, et al. Effect of periodontitis on overt nephropathy and end-stage renal disease in type 2 diabetes. Diabetes Care. 2007 Feb;30(2):306-11.

16 Teeuw WJ, Gerdes VE, Loos BG. Effect of periodontal treatment on glycemic control of diabetic patients: a systematic review and meta-analysis. Diabetes Care. 2010 Feb;33(2): 421-7.

17 Bowyer V, Sutcliffe P, Ireland R, Lindenmeyer A, Gadsby R, Graveney M, et al. Oral health awareness in adult patients with diabetes: a questionnaire study. Br Dent J. 2011 Sep; 211(6):E12.

18 Yuen HK, Wolf BJ, Bandyopadhyay D, Magruder KM, Salinas CF, London SD. Oral health knowledge and behavior among adults with diabetes. Diabetes Res Clin Pract. 2009 Dec;86(3):239-46.
19 Eldarrat AH. Awareness and attitude of diabetic patients about their increased risk for oral diseases. Oral Health Prev Dent. 2011; 9(3):235-41.

20 Faden AA, Alsalhani AB, Idrees MM, Alshehri MA, Nassani MZ, Kujan OB. Knowledge, attitudes, and practice behavior of dental hygienists regarding the impact of systemic diseases on oral health. Saudi Med J. 2018 Nov; 39(11):1139-47.

21 Allen EM, Ziada HM, O'Halloran D, Clerehugh V, Allen PF. Attitudes, awareness and oral health-related quality of life in patients with diabetes. J Oral Rehabil. 2008 Mar;35(3): 218-23.

22 Poudel P, Griffiths R, Wong VW, Arora A, George A. Knowledge and practices of diabetes care providers in oral health care and their potential role in oral health promotion: a scoping review. Diabetes Res Clin Pract. 2017 Aug;130:266-77.

23 International Diabetes Federation. IDF diabetes atlas. 2015, 7th ed. http://www. diabetesatlas.org/ (accessed 25/11/2017).

24 American Diabetes Association. 3. Comprehensive medical evaluation and assessment of comorbidities. Diabetes Care. 2017 Jan;40 (suppl 1):S25-32.

25 Esmeili T, Ellison J, Walsh MM. Dentists' attitudes and practices related to diabetes in the dental setting. J Public Health Dent. 2010; 70(2):108-14.
26 Jimenez M, Hu FB, Marino M, Li Y, Joshipura KJ. Type 2 diabetes mellitus and 20 year incidence of periodontitis and tooth loss. Diabetes Res Clin Pract. 2012 Dec;98(3):494-500.

27 Costa KL, Taboza ZA, Angelino GB, Silveira VR, Montenegro R Jr, Haas AN, et al. Influence of periodontal disease on changes of glycated hemoglobin levels in patients with type 2 diabetes mellitus: a retrospective cohort study. J Periodontol. 2017 Jan;88(1):17-25.

28 Bell KP, Phillips C, Paquette DW, Offenbacher S, Wilder RS. Dental hygienists' knowledge and opinions of oral-systemic connections: implications for education. J Dent Educ. 2012 Jun;76(6):682-94.

29 Al-Khabbaz AK, Al-Shammari KF. Diabetes mellitus and periodontal health: dentists' knowledge. Med Princ Pract. 2011;20(6):53844.

30 Boyd LD, Hartman-Cunningham ML. Survey of diabetes knowledge and practices of dental hygienists. J Dent Hyg. 2008;82(5):43.

31 Hema TS, Prasad KV, Shetty PJ. Dentist's attitudes and practices related to diabetes in dental settings in Hubali-Dharwad city. Int $J$ Dent Health Sci. 2014;1:879-89. 